\title{
E-Learning Over Mobile Phone Technology: Best Practices and Guidelines
}

\author{
doi:10.3991/ijim.v3i3.950 \\ F. Khaddage, A. Chonka and W. Zhou \\ Deakin University, Melbourne, Australia
}

\begin{abstract}
Over the past decade, we have seen a large advancement in picture and sound quality that is now offered through mobile phones. Through this advancement we have now seen the development of mobile phones that have cameras that can take picture and videos. They can also play music, provide internet services, pay-per-view $\mathrm{TV}$, radio, and even hi-res computer games are now becoming available to mobile phone users. With all these available services that are now offered through mobile phone, we now believe that those who provide E-learning materials can now provide their presentations that is clear and concise, but also make their materials fun and enjoyable so that it does not have the opposite effect of learning. In this brief paper, we covered some of the best practices and guidelines that course designers could use in guiding them to provide $E$ learning material over mobile phones.
\end{abstract}

Index Terms-E-Learning, Mobile Phones, Best Practices, Multi-media

\section{INTRODUCTION}

Up to very recently, it has not been feasible to provide learning over mobile phone technology, due to constrains of phone limitation of sound, screen size, and limited services (Up to a few years ago, Mobile Phones could only send small text messages and send/receive phone calls, which was not very conducive to learning ). Now with advancements in mobile phone services, these technology limitations are being overcome, with flashy new screens, good quality speakers, Internet \& Web Services and good quality software.

Currently, E-Learning is considered a do-it-self or self paced learning system, with the advancement in DVD/CD's, Computing, Software development, Internet, World Wide Web, and Mobile technology. But with all these advancements in technology that E-Learning uses, we should not forget its central objective, which is to provide learning content [6].

With these new advancements comes problems that need to be addressed to by those who are providing Elearning material, such as re-training with the new software technology, understanding of limitations (what can and can not be done with the new technology), and maybe old ideas of learning need re-addressed to adapt with this new environment. For example, though E-learners do not want to over do their e-learning content with flashy graphics or sounds, which instead of attracting e-learners to their content, it may in fact distract them [7].

Other problems facing E-learners are, how interface design works, how to layout their content, what multimedia content they want, display, connectivity, ease of use and navigation and accessibility and display. Finally, and probably one of the biggest problems, is E-learners design their learning content on basis of modern phones, which means those low-tech mobile phones, may only have zero to minimum access to the learning content provided.

In this brief work, we follow along the same lines as Won [6][7][9] evaluations, but from the specific point of view of mobile phones. We also cover some of the best practice and guidelines for designing a mobile phone learning content, which can then be used by course designers to train themselves, so that their learning content is effective, interactive and capable of transferring learning content to others without any major obstacles. The rest of this paper is as follows: Section II cover the related work, Section III covers our best practice and guidelines, Section IV covers our evaluation of these best practices and guidelines, and finally, our conclusion is covered in Section IV.

\section{RELATED WORK}

In this section, we briefly cover the area of technology use in the area of E-Learning Environment.

In the paper by LittleJohn et. al. [9], they studied the key characteristics of learning resources which affected changes in learning environments. From this study, they then applied their results to existing frameworks, in which they were able to show an outline of relationships between resources, the users of these resources and explore the reason why the user chose those particular resources. Though this paper deals with e-learning and some technology in detail, it does not consider the factors of mobile technology (like mobile phones). Instead the main focus is on technology that is well established, and does not seem to be a problem, except with mobile technology. There are other technological factors, such as screen resolution, signal availability, signal reliability and audio sound quality, which in the area of mobile technology need to considered.

A closer paper that is relative to e-learning in mobile phones by Jeong et. al [9]. In their paper, they examined the advances of technologies, in regards to learning, and pointed out that if technology is used incorrectly, it leads to a distracted learning. Some of the disadvantages that they pointed out are:

I. Inaccessible or difficult-to-access visual or audio aids.

II. Mobile Phones have small screens and so they can not be built in the same way as other e-learning web applications.

III. Over use of textual aids, so that it leads the learner to turn a blind eye to the actual learning content. For example, cool graphics, like in game of World of 
Warcraft, but they can also be very distracting as well.

IV.Finally, fuzzy terms, the use of acronyms and even concepts, which are not explained can lead to bad learning concepts.

Although the paper by Jeong et. al. outlines some of the problems we discuss in this paper, they did not really propose any solutions to these problems. Also what is missed within their paper is that with mobile phones, the language that is used has also changed. For example, sending a text message, in which you insert the word "lol" (Laugh out Loud), this is covered by point IV, but the question is does this lead to bad learning?

The last paper we discuss is the paper by Kim [6], in which he covers some of the technologies (media and Web 2.0), in which to improve the effectiveness of elearning. As Kim points out that if 'pure' e-learning has limitations, and those designers of e-learning content need to know these limitations. Because if they do not, then Kim points out that more than likely, it would lead to poorly created content, probably boring or dry, and lack of motivation to learn. All of these, as Kim points out, will lead to lower learning efficiency and to lower learner engagement compared to a traditional learning. Although Kim's paper has some relevance to e-learning within mobile phones, since it can use multi-media through the use of web, but the problem of the paper is that, it does not give any guidelines if these events happen. Instead, Kim's paper is more proactive than reactive to situations that arise in e-learning.

\section{GuideLines and Best Practices to Mobile Phone E-LEARNING}

Traditional design guidelines and methods used for computer and web-based applications may not be applicable to a mobile learning environment, because mobile phones have unique features, limited bandwidth, unreliability of wireless networks, as well as changing context Therefore, it is essential to develop best practice and design guidelines if followed by course designer and developer can improve the usability of mobile applications for learning purposes.

The contribution of this paper is to propose a best practice and design guidelines for mobile learning applications for mobile phones, since it has been found that around $94 \%$ of university students have them [1][2], [3].

In light of the results from [1][2][3], learning institutes like University, should now move to a specifying set of best practice and design guidelines for designing learning content for mobile phone technology. With this work, it is the first step towards the development of these specifics best practice and design guidelines, in which we briefly overview of existing research in the area. Then setup a generic technical design guidelines and recommend some of the best practice's that is needed to support the mobile technology.

Below is a list of technological aspects which should be considered when designing a mobile phone learning platform it is based on the W3C Mobile Web Best Practices Basic Guidelines (MWBP) as this was the first deliverable of the working group and echoes the recognized best practices established since 2000 in the Mobile Web community [4],[5].
1. Use of valid XHTML-MP ensures that pages will work on most mobile devices as well as on desktop browsers. Non-validating markup may not display correctly, in particularly on older phones, nonvalidating XHTML-MP may also not render, and the student may only see an error message in their browser.

2. Many mobile devices do not support embedded objects or scripts. Sometimes it is not possible for students to load plug-ins to add support. Even when a device does support scripting, still scripting increases power consumption, thus decreasing battery life this is a major issue for mobile devices. Therefore content must be designed with this in mind.

3. Images should be kept as small as possible. Most mobile devices screens are less than 200 pixels and downloading images can increase the time to load the page. Therefore making pages readable without images allows student to browse the page in text mode, which reduces download times and cost.

4. Page sizes and style-sheets should be kept small since large pages take longer to load and, on most networks, increase data charges.

5. Use of tables to include information should be avoided, unless they are known to be supported by a particular student mobile device. Page layout is more efficiently accomplished using CSS (cascade style sheet) and the resulting layout is easier to render in a narrow context.

6. Use of frames should be avoided, as many mobile devices do not support them, and because they cause a number of usability problems

7. Correct character encoding should be specified for all pages. If it is not specified then the page may display with strange characters. Correct character encoding is essential to ensure that pages render correctly on any mobile device. Different character encodings are required for different document types. XML documents should always have a UTF-8 character set [5].

8. Providing an access key with a link gives students a convenient way to access their information. Access keys are particularly useful when used consistently across the learning site, as they enable students to jump quickly to their chosen section without having to scroll.

9. Structural markup, headings and sub-headings should be used, as it allows easier adaptation of content where it needs to be divided into several pages, as well as potentially facilitating access to the sections of the document that a student is interested in. Where headings are used they should be used in accordance with the specification, i.e. they should be properly nested according to their level.

10. Educational pages which contain learning content, should not rely on too many external resources, as each external resource listed in a page must be separately downloaded to the student device, this can add to the time and cost of viewing a page.

11. Use cache information can reduce the need to reload resources such as images and style-sheets, thus reducing download times and costs. Caching is particularly important for mobile devices due to the high network latencies typically experienced on mobile networks [5]. 
12. Given the typical input limitations of a mobile device, the interface must as far as possible minimize student input. Where possible, use selection lists, radio buttons and other controls that do not require much typing.

13. Keep It Simple, the best advice for creating a strong mobile learning content and information architecture is to keep it as simple as possible.

14. Student centered design should be adapted, as understanding the needs and wants of students help humanize the process and make interaction much easier. Few crucial questions designer should ask themselves, HOW and WHERE students will interact with the learning content. WHAT type of learning content is important for the learning process?

\section{Evaluations of These GuideLines And Best PRACTICES}

Since our recommendations for best practices and design guidelines should be validated, we conducted a comparative technological evaluation of 4 commonly used mobile phones. So that through this evaluation, we will be able to assess the mobile phones' efficiency, robustness, scalability, effectiveness, functionalities and capabilities, to support e-learning within a mobile phone.

In particular we looked at what technologies these mobile phones support, that can help students view and retrieve learning content without any problems. We investigated the following mobile phone brands: Nokia N70 Samsung SGH E530, Sony Ericson W880i, and the 3G iphone.

To be specific we have listed a set of criteria for this evaluation, and they are as follow:

- Internet services: they are normally designed to allow access from most mobile phone devices. It concerns with the ease of using email, and deals with most internet features.

- Web services: This also deals with internet searches, maps, news, calendars, calculators and the integration of web services applications.

- Software: Java support, as most new mobile phones integrate java applications in J2ME.

- Quality graphics: this includes display modalities, size of display, brightness, graphic quality and time taken to retrieve a certain image.

- Sound: this covers clarity, loudness and quality of the audio, and if it supports MP3 and a variety of other audio format.

- Folder space: if it offers folders for data storage and organization of resources and information.

- Video camera service: this deals with the quality of streaming video, and if they can record at a different resolution with no blocky distortion and frame jumps.

- Battery life: the length of time needed before recharging.

According to the results in Table 1, the comparative evaluation of the latest the mobile phone is, the more efficient it is in supporting various technological capabilities for learning. We then extended the Table 1 evaluation into table 2, for 1 to represent bad to 5 to represent good, as we went through the feature of the mobile phones. We then show the results of Table 2, in Figure 1. It should be noted that learning institutes, like the universities, do not have a standardized mobile phones in which all student will have. Thereby, with the best practice and design guidelines, it was decided that learning content should be accessible to what is the average services available to each phone.

TABLE I.

EVALUATION CRITERIA AND SELECTED MOBILE PHONE BRANDS

\begin{tabular}{|l|c|c|c|c|}
\hline \multicolumn{1}{|c|}{ Criteria } & $\begin{array}{c}\text { Nokia } \\
\text { N70 }\end{array}$ & $\begin{array}{c}\text { Samsung } \\
\text { SGH E530 }\end{array}$ & $\begin{array}{c}\text { Sony Ericson } \\
\text { W880i }\end{array}$ & 3G iphone \\
\hline Internet Services & Yes & yes & yes & yes \\
\hline Web Services & some & limited & yes & yes \\
\hline Software (Java) & Some & some & yes & some \\
\hline Quality Graphics & Average & average & good & Excellent \\
\hline Sound & Average & average & good & good \\
\hline Folder Space & yes & limited & yes & Yes \\
\hline $\begin{array}{l}\text { Video Camera } \\
\text { Services. }\end{array}$ & Yes & Yes limited & yes & good \\
\hline Battery life & average & average & good & good \\
\hline
\end{tabular}

TABLE II.

EVALUATION CRITERIA AND SELECTED MOBILE PHONE BRANDS.

\begin{tabular}{|l|c|c|c|c|}
\hline \multicolumn{1}{|c|}{ Criteria } & $\begin{array}{c}\text { Nokia } \\
\text { N70 }\end{array}$ & $\begin{array}{c}\text { Samsung } \\
\text { SGH E530 }\end{array}$ & $\begin{array}{c}\text { Sony Eric- } \\
\text { sonW880i }\end{array}$ & 3G iphone \\
\hline Internet Services & 5 & 5 & 5 & 5 \\
\hline Web Services & 3 & 2 & 4 & 5 \\
\hline Software (Java) & 2 & 2 & 5 & 3 \\
\hline Quality Graphics & 3 & 3 & 4 & 5 \\
\hline Sound & 2 & 2 & 4 & 5 \\
\hline Folder Space & 5 & 2 & 4 & 5 \\
\hline $\begin{array}{l}\text { Video Camera } \\
\text { Services. }\end{array}$ & 2 & 3 & 4 & 5 \\
\hline Battery life & 2 & 2 & 4 & 5 \\
\hline
\end{tabular}

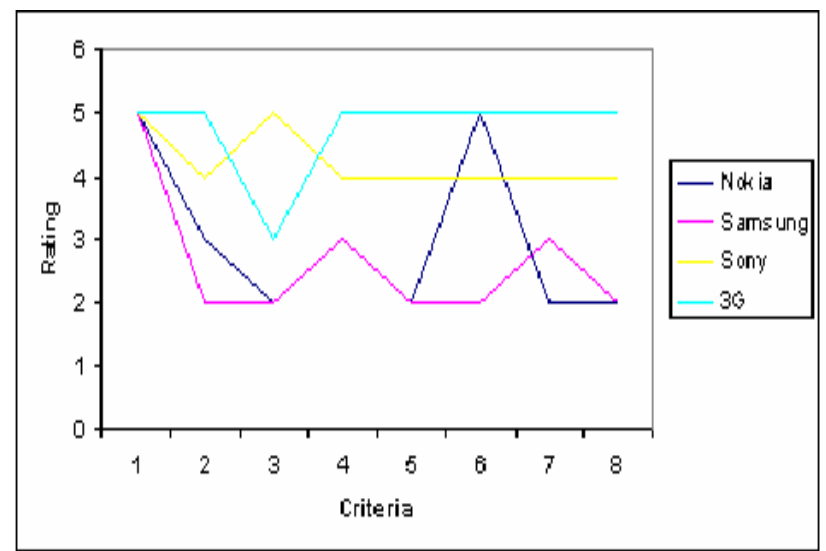

Figure 1. Criteria selection based from the results in Table 2. As displayed, the $3 \mathrm{G}$ mobile phone is currently one of the best mobile phones that provide a lot of the features that can be used for E-Learning. 


\section{E-Learning Over Mobile Phone Technology: Best Practices And Guidelines}

\section{CONCLUSION}

In this paper we recommended a set of technological guidelines and best practices, to be adapted by course designers when designing a mobile learning content.

Our further work will focus on broadening the range of techniques in the evaluation process. In particular, we wish to physically test learning content accessibility by learners themselves. And also to further compare performance of certain mobile phones for certain content, and to assess their efficiency related issues, plus the effectiveness of the delivered learning content.

\section{REFERENCES}

[1] Australian Research Council Report http://polsc.anu.edu.au/ staff/wajcman/pubs/Report on Mobiles and Work Life Balance June 07.pdf Accessed 25 October 2008

[2] Australian mobile telecommunication association, 2007, The Impact of the Mobile Phone on Work/Life Balance

[3] University of South Australia: Key Statistics - Number of Students Produced by Planning and Assurance Services http://www.unisa.edu.au/ pas/bai/keystatistics/UniSAKeyStatisticsStudentNumbers.pdf Accessed 11 October 2008

[4] Christian Lindholm, Turkka Keinonen, Mobile Design Patterns, Mobile Usability: How Nokia Changed the Face of the Mobile Phone http://patterns.littlespringsdesign.com Accessed 12 November 2008

[5] Mobile Web Best Practices 1.0,Basic Guidelines W3C Recommendation 2008 Jo Rabin, mTLD Mobile Top Level Domain,Charles McCathieNevile, Opera Software http://www.w3.org/TR/mobile$\underline{\mathrm{bp} / \# \mathrm{~d} 0 \mathrm{e} 116}$ Accessed 12 November 2008
[6] Jeong, O.K, and Kim, W (2008), "Using Technologies to Improve E-Learning”, Journal of Object Technology, vol. 7, no. 8, November December 2008, pp 51-56 http://www.jot.fm/issues/issue 2008 11/ $\underline{\text { column5 }}$

[7] Kim, W, (2008), "Towards a Definition and Methodology for Blended Learning," in Proc. Of the First International Workshop on Blended Learning, August 2008, Edinburgh.

[8] Littlejohn A, Falconer, I and Mcgill, L, (2006), 'Characterising Effective eLearning resources', Science Direct, Elsevier Ltd www.elsevier.com/locate/compedu

[9] Jeong, O.K, and Kim, W (2008), "On Properly using Technologies to make E-Learning Effective", Springer-Verlag Berlin Heidelberg, ICWL 2008, LNCS 5145, pp. 1-7, 2008

\section{AUTHORS}

Ms. Ferial Khaddage is a current $\mathrm{PhD}$ candidate with the Faculty of Science and Technology, at Deakin University, Australia. (e-mail: khaddage@deakin.edu.au).

Mr. Ashley Chonka is a current $\mathrm{PhD}$ candidate with the Faculty of Science and Technology, at Deakin University, Australia. (e-mail: ashley@deakin.edu.au).

Professor Wanlei, Zhou, PhD, DSc, is the Interim Head of School, with the School of Information Technology at Deakin University, Australia. (e-mail: wanlei.zhou@deakin.edu.au).

Submitted, May 29, 2009. Published as resubmitted by the author(s) on June 3rd, 2009. 